\title{
FONOAUDIOLOGIA E PEDAGOGIA ESPECIAL EM UM SISTEMA ESCOLAR INCLUSIVO NA ALEMANHA
}

\author{
Jörg Mussmann* \\ Nadia Azevedo**
}

RESUMO: A pedagogia tradicional e a terapia tradicional para os distúrbios da fala e linguagem (Sprachheilpädagogike) na Alemanha, áreas de ensino especializado das ciências da educação, têm sido requisitadas a definir recursos educacionais justificáveis para um sistema escolar inclusivo e reestruturado. Este trabalho pretende refletir sobre as vantagens da pedagogia inclusiva na Alemanha, fornecendo dados comparativos entre a pedagogia tradicional, separatista e a inclusiva. Recursos institucionais e didáticos bem desenvolvidos têm mostrado, entretanto, perspectivas úteis em um sistema inclusivo, quando o princípio de subsidiaridade é seguido. A história e a evolução da área desta pedagogia especial poderiam fornecer informações acerca dos limites e possibilidades da educação inclusiva, principalmente para alunos com distúrbios da linguagem. Os resultados apontam para o fato de que em diferentes níveis e pontos de transição, pode-se trabalhar diretamente com o suporte à criança ou indiretamente com consultoria ou formação contínua da equipe pedagógica docente para a criança.

Palavras-chave: Educação Inclusiva; Sprachheilpädagogik; Teoria do Profissionalismo.

\section{SPEECH THERAPY AND SPECIAL EDUCATION IN INCLUSIVE SCHOOL SYSTEM IN GERMANY}

ABSTRACT: The traditional Sprachbeilpädagogik, the speech and language pedagogy and therapy in educational contexts in Germany, is currently being challenged to define as a specialized educational domain of education and educational science their resources with a justifiable educational theory for the inclusive restructuring of the school system. However, well-developed educational and institutional resources show useful perspectives in an inclusive system if the principle of subsidiarity is followed. A network-based organization would be one way. The restructuring of the special schools for pupils with speech and language disabilities would be another way.

Keywords: Inclusive Education; Speech Therapy; Theory of Professionalism.

\footnotetext{
*Doutor em Educação Inclusiva. Instituto de Pedagogia Especial e Curativa Departamento de Pedagogia para os Distúrbios de Fala e Linguagem Universidade de Giesen - Alemanha. E-mail: Joerg.Mussmann@uni-hamburg.de

* *Doutora em Letras e Linguística Lingüística pela Universidade Federal da Paraíba (UFPB), Professora e Pesquisadora da Pós-graduação em Ciências da Linguagem da Universidade Católica de Pernambuco (UNICAP). E-mail: nadiaazevedo@unicap.br
} 


\section{A PEDAGOGIA ESPECIAL E A FONOAUDIOLOGIA NA ALEMANHA}

A consolidação da disciplina científica da pedagogia especial para distúrbios de fala e linguagem entre medicina e pedagogia geral, bem como a criação de uma ciência institucionalizada sobre distúrbios de fala e linguagem na Alemanha e na Áustria-Hungria exerceram, no início do século XX, uma influência decisiva na formação de sistemas de cuidados de terapia da fala, principalmente nos EUA. De acordo com as tradições alemãs, não foram apenas as evidências médicas que obtiveram conhecimento acerca dos distúrbios da fala, mas também as abordagens pedagógicas para o tratamento de unidades atingidas, em uma compreensão técnica de lenta evolução dos distúrbios da fala e da linguagem. Na Europa e no mundo anglo-americano, durante as duas primeiras décadas do século XX até a Primeira Guerra Mundial, seguiu-se uma ampla discussão das obras clássicas sobre articulação, gagueira e terapia de voz de Kussmaul (1877), Gutzmann, A. (1888), Nadoleczny (1926), Froeschels (1913) e Rothe (1925). Este domínio do desenvolvimento de terapias de fala ficou conhecido como German School (WEST, 1966).

$\mathrm{Na}$ Alemanha, este desenvolvimento técnico foi dividido em dois grupos de trabalho que, mesmo tendo trabalhado com a mesma clientela e em parte também com técnicas e métodos idênticos, possuíam diferentes áreas de responsabilidade e atuação nos sistemas de educação e saúde.

A fonoaudiologia desenvolveu-se na Alemanha a partir da foniatria e, em 1905, foi instituída por Gutzmann, H. (1912) como disciplina de uma universidade em Berlim. No decorrer do século XX, este campo de estudo foi oferecido como formação profissional. Os fonoaudiólogos foram considerados, por muito tempo, na Alemanha, como profissionais paramédicos não acadêmicos. A teoria que serviu de base para capacitação profissional dos fonoaudiólogos tem suas raízes na foniatria, bem como no pensamento médico sobre a forte integração entre distúrbios de fala e linguagem às funções e estruturas neurais.

Paralelamente, desenvolveu-se no sistema educacional o perfil profissional do pedagogo especializado em crianças e jovens com distúrbios da fala e da linguagem (os pedagogos para os distúrbios de fala e linguagem). Com relação ao conteúdo terapêutico da fonoaudiologia clínica em desenvolvimento e do conteúdo pedagógico da pedagogia para surdos-mudos, 
foi instituído para estes pedagogos especializados um novo campo de trabalho nas escolas primárias. Já em 1883, foram oferecidos os assim chamados Sprachbeilkeurse (cursos para pessoas com dificuldades na fala) aos alunos gagos. Havia medidas públicas das autoridades escolares paralelamente às aulas regulares nas escolas. Os pedagogos especializados nesta área realizavam exercícios sistemáticos de tratamento e prática de linguagem. No decorrer da institucionalização da pedagogia especial acadêmica para alunos com distúrbios de fala e linguagem, foi debatida a questão da combinação de objetivos terapêuticos específicos da linguagem com objetivos gerais de ensino na sala de aula. A resposta a estas questões metódicas deu origem na Alemanha a um grupo de trabalho de pedagogos especializados e autônomos, que, no contexto escolar, poderiam oferecer tanto terapias como aulas. Para este trabalho, são oferecidas na Alemanha até hoje escolas separadas, que se caracterizam principalmente por classes menores. Os alunos que frequentam uma escola especial deste tipo geralmente não recebem dos seguros de saúde legais na Alemanha isenção de custos para terapias da fala com fonoaudiólogos do sistema de saúde, as quais são prescritas por um médico. Somente em casos de distúrbios de fala ou linguagem muito graves, os fonoaudiólogos podem trabalhar em conjunto com a equipe de professores especializados nestas escolas especiais. Geralmente, não existe uma relação entre o trabalho terapêutico dos fonoaudiólogos nas escolas e o conteúdo das aulas.

Com a convenção das Nações Unidas sobre os direitos das pessoas com deficiência, agora em vigor também na Alemanha, o sistema escolar separativo neste país vem sendo gradativamente reestruturado. As escolas especiais separadas também apresentam, de acordo com diferentes interpretações jurídicas da convenção da ONU, uma discriminação dos alunos com distúrbios de fala e linguagem. O objetivo é ter uma aula comum para alunos com e sem deficiências em uma escola regular. Com isto, surge a questão de como o campo de trabalho atual dos pedagogos especializados em crianças com distúrbios de fala e linguagem será modificado ou se este campo de trabalho será totalmente assumido nas escolas pelos fonoaudiólogos médicos do sistema de saúde.

Desta forma, este trabalho pretende refletir sobre as vantagens da pedagogia inclusiva na Alemanha, fornecendo dados comparativos entre a pedagogia tradicional, separatista e a inclusiva. 
Trata-se de uma pesquisa qualitativa e descritiva, que pretende historiar o percurso da Pedagogia Especial separatista, na Alemanha, até os dias de hoje, quando a Educação Inclusiva já é uma questão fundamental. A metodologia utilizada no trabalho parte do levantamento bibliográfico da história da Educação Inclusiva na Alemanha.

As linhas teóricas de desenvolvimento profissional, as contribuições históricas e perspectivas de especialistas na área de Fonoaudiologia e Pedagogia Especial na Alemanha estão sendo reconstruídas neste trabalho.

\section{PROGRAMAS E CONCEITOS DA PEDAGOGIA ESPECIAL NA ALEMANHA}

Durante as discussões científicas e políticas na convenção dos direitos das pessoas com deficiência nas Nações Unidas, desenvolveu-se dentro dos campos da pedagogia especial e da pedagogia curativa na Alemanha uma extensa nomenclatura programática para a autorreflexão acerca do verdadeiro profissionalismo da pedagogia especial nos grupos de trabalho dos pedagogos especializados (cf. ALBRECHT; HINZ; MOSER, 2000; MOSER, 2005; HINZ, 2009).

Para isso, também foram discutidos na pedagogia para os distúrbios de fala e linguagem da Alemanha os desenvolvimentos conceituais e programáticos (GLÜCK; MUSSMANN, 2009). Com um programa de pedagogia inclusiva para distúrbios da língua e da fala, deve-se destacar a necessidade de conhecimentos específicos, relevantes, reflexivos e práticos dos pedagogos, podendo estes ser fornecidos como recurso competente para um apoio especializado em um sistema escolar inclusivo (cf. HINZ, 2009). Assim, devem-se destacar acerca do campo de profissionalismo, caracterizado por sua exclusividade histórica e objetiva, a reflexão, a prevenção e a intervenção em relação ao desenvolvimento e ao uso da língua (como áreas temáticas e reflexivas tanto científicas quanto práticas, como também, por exemplo, do desenvolvimento cognitivo, socioemocional e corpóreo-motor), em suas consequências metódicas com relação à sua clientela, para que pessoas com disfunções na língua, na fala, na voz e na competência comunicativa jamais sejam excluídas. 


\section{INCLUSÃO NA PEDAGOGIA PARA OS DISTÚRBIOS DE FALA E LINGUAGEM}

A tradicional e separativa pedagogia para os distúrbios de fala e linguagem na Alemanha, como domínio pedagógico das ciências da educação e capacitação, tem sido requisitada a definir recursos educacionais justificáveis para um sistema escolar inclusivo e reestruturado (cf. GLÜCK; MUSSMANN, 2009). Isto representa, por suas raízes históricas na foniatria e no seu desenvolvimento parcial da fonoaudiologia clínica, um desafio. O desenvolvimento viável sustenta-se em abordagens decididamente pedagógicas e não institucionalizadas com autores tais como Lütje-Klose (1997), Welling; Kracht (2002) ou Lüdtke (2010). Desta maneira, trata-se da justificativa de conceitos teórico-profissionais, a partir das quais devem ser inferidas formas de tratamento diretas (terapia, aula) e indiretas (consulta) que, por sua vez, precisam ser demonstradas institucionalmente em um sistema escolar inclusivo. (cf. também MUSSMANN, 2010).

Uma pedagogia integradora acerca das disfunções da linguagem e da fala em um sistema escolar inclusivo deve fornecer informações acerca das quais serão as propostas não institucionalizadas que ainda poderão estar disponíveis durante a dissolução política do sistema escolar separativo na Alemanha.

\section{PONTOS DE PARTIDA DIDÁTICO-CONCEITUAIS COM ENFOQUE NA LINGUAGEM}

A pedagogia para os distúrbios de fala e linguagem desenvolveu uma terminologia variada para conceitos e métodos de uma terapia escolar da fala (WELLING, 2006, p. 205), que consegue combinar objetivos de terapia de fala e objetivos de capacitação na sala de aula. A aula com objetivos fonoaudiológicos deve, acima de tudo, ser concebida como uma aula didática e não institucionalizada (BRAUN, 2004, p. 43f.). Ela deve produzir situações didáticas, nas quais se desperte o interesse pelo desenvolvimento das competências de atuação linguística (suporte). Isto vem sendo praticado diretamente através de trabalhos didáticos próprios em sala de aula e trabalhos em conjunto (team-teaching) ou, indiretamente, através do acompanhamento de um pedagogo comum. No trabalho direto, devem ser integradas intervenções especificamente linguísticas individualizadas 
(terapia), que permitam a compreensão de usos linguísticos tradicionais e que assegurem a experimentação e a prática do procedimento linguístico (cf. DRAVE et al., 2000, p. 232).

Ao considerarmos clientela predominante do suporte pedagógico com enfoque na linguagem, crianças com transtornos definidos do desenvolvimento psicológico da linguagem (GRIMM, 2003), a pedagogia para os distúrbios de fala e linguagem na Alemanha sistematizou três procedimentos que se diferenciam tecnicamente de acordo com seus níveis e modalidades:

- Pattern Practice: Exercícios de amostras de frases, alta frequência de expressões modelo e exercícios do tipo "out of context imitation treatment" (CAMARATA; NELSON, 1992);

- Abordagem de desenvolvimento proximal (DANNENBAUER, 1999): Em contextos situados de aprendizagem e vivência, são apresentadas estruturas linguísticas alvo, de expressão infantil, bem como o tratamento geral, sendo anteriores (modeling) ou posteriores (recasts) a estas estruturas. A proximidade orienta nas fases de desenvolvimento dos níveis linguísticos, p. ex., no âmbito da gramática, de acordo com Clahsen (1986); e

- Procedimentos orientados para a reflexão: Dicas de reflexão e recuperação das propriedades estruturais e funcionais da língua, também através de visualizações e imagens escritas. Podem-se implementar modelos metafonológicos (pares mínimos, p. ex., /mapa/ - /sapa/), metassemânticos (p. ex., trabalho com campos semânticos: $O$ que combina um com outro?), metassintático (p. ex., perguntas alternativas tipo recast. O cavalo está dentro do estábulo ou fora dele?) ou ainda metapragmáticos (refletir sobre ironia e humor).

O conceito de otimização contextual implica atualmente sistematizar procedimentos através da orientação de causa, mudança de modalidades, orientação de recursos e contextos ("within context conversational treatment" CAMARATA; NELSON, 1992) como aulas terapêutico-linguísticas (MOTSCH, 2006; BERG, 2008).

\section{ENTRE PROVINCIANISMO LINGUÍSTICO E AUTODISSOLUC̣ÃO PROFISSIONAL}

A questão principal no âmbito da conceitualização didática de uma pedagogia específica dos distúrbios da língua e da fala deu-se acerca das estruturas da integração de terapia e sala de aula (WERNER, 1995, p. 211). Esta questão foi tratada por alguns autores com a busca de definir 
ambas as categorias de tratamento como sendo idênticas (BRAUN, 1983). No que diz respeito aos requisitos de ensino prático, muitas vezes, o lado tecnológico desta abordagem tentou tecnicamente adicionar mais um pilar nos planos de aula (WELLING, 2007, S.958). O foco nas peculiaridades linguísticas, províncias linguísticas da realidade vivida pelas crianças, diferencia-se claramente pelos métodos de desenvolvimento de aulas terapêutico-linguísticas. O que, para os pedagogos especializados (professores de alunos com distúrbios linguísticos), pode representar uma fonte imensurável de ideias didáticas praticáveis nas escolas separadas (escolas para alunos com distúrbios linguísticos), traz à tona a questão da importância da criação de objetivos em uma sala de aula comum ou em uma escola inclusiva. Um motivo para a redução da técnica exclusiva de se combinarem estruturas didáticas e terapêutico-linguísticas de tratamento e também para a abstenção de questões fundamentais acerca da estrutura escolar poderia ser atribuído historicamente a um aspecto estrutural da profissão. A área de atuação é caracterizada como nenhuma outra por um traço estrutural que até hoje representa uma superfície de projeção de uma discussão teórico-profissional entre saúde e sistema de ensino. A relação das categorias de tratamento aula e terapia de fala foi e é, neste sentido, continuamente um ponto central para este discurso estrutural. Esta discussão representa na pedagogia para os distúrbios de fala e linguagem um dilema formado historicamente entre objetos de atuação diferentes e concorrentes. A diferenciação funcional na ciência e pesquisa levou a pedagogia para os distúrbios de fala e linguagem nas áreas atuais de atuação aos domínios de reflexão:

- da "Medicina para Distúrbios de Fala e Linguagem" (Sprachbeilkunde) (Em 1905, por (1912), H. com enfoque médico, "Escola de Berlim" (Berliner Schule)) mais tarde foniatria/audiologia pediátrica;

- fonoaudiologia (Em 1924, por Fröschels com enfoque psicológico, "Escola de Viena" (Wiener Schule); e

- da "Pedagogia para Surdos-Mudos" (a partir de cerca de 1800, com enfoque didático-linguístico).

E, com isso, hoje, ao aspecto estrutural de língua e fala (linguística, medicina), pessoal (psicologia, pedagogia) e da orientação social (pedagogia), na teoria e na prática.

Em uma difusão dos domínios linguísticos específicos da pedagogia para os distúrbios de fala e linguagem na Alemanha através de relações de fatores contextuais internos (orientação pessoal) e externos, tanto distais quanto 
proximais (orientação social), teme-se uma autodissolução funcional. Com isso, na discussão teórico-profissional acerca da pedagogia para os distúrbios de fala e linguagem na Alemanha, tem-se praticado um discurso, no qual não se deve repreender a preservação da instituição e da estrutura disciplinar. Estas objeções são justificadas, portanto, se, após a desinstitucionalização da pedagogia para os distúrbios de fala e linguagem (através da evolução de sistemas de tipos escolares separativos para tipos inclusivos), uma desprofissionalização fosse introduzida através da orientação contextual da pedagogia especial, o que levaria à dissolução de categorias de tratamento orientadas para cada pessoa (aulas, medidas de apoio individualizadas) e sua tarefa consistiria unicamente em uma forma de consultoria organizacional.

\section{DESENVOLVIMENTOS DIDÁTICOS COM ENFOQUE NA LINGUAGEM}

As conceitualizações didáticas, orientadas sociologicamente, mesmo tendo em seu enfoque linguístico fatores sociais e contextuais, ainda possuem uma relação com as características e fenômenos estruturais e linguísticos. O tratamento linguístico e sua interpretação com intenções comunicativo-pragmáticas e todas as implicações cognitivas e socioemocionais pertencem ao processo da coconstrução cooperativa (BINDEL, 2007). Na melhor das hipóteses de uma crise comunicativa da implementação linguística (HOMBURG, 1993, p. 119), a compreensão e o tratamento linguísticos desencadeariam um processo idioletal da comunicação como compromisso por meio da generalização do outro (UNGEHEUER, 1987), com base em hipóteses sobre o conhecimento e as expectativas sociais e emocionais. A língua pretende principalmente levar ao interlocutor uma perspectiva definida (GRAUMANN, 1994), bem como atingir metas pessoais. A língua pressupõe uma interpretação interpessoal (TOMASELLO, 2002) e é uma estratégia cognitiva: sua antecipação sendo o que o ouvinte deduz e como ele reage, e sua compreensão devendo ser aquilo que não é expresso (Theory of Mind, ASTINGTON, 2006).

Neste ponto, é importante destacar o planejamento cognitivo e a construção linguística diretamente no uso da língua (thinking for speaking, SLOBIN, 1996). A atividade principal diz respeito à construção de textos orais, frases contextualizadas, tais como contos. A comunicação relaciona-se, 
desta maneira, à intenção do falante, à situação atual, aos endereçados e ao episódio e função do encontro social. A língua é o recurso, com o qual se pode reagir variavelmente, para saber como se deve falar em situações sociais. O aprendizado de línguas através de diálogos significa o aumento da inclusão ativa da realidade no uso da língua em toda sua complexidade. É essencial a introdução à cultura teórica (fala letrada): amostras de expressões, reflexão de expressões de acordo com as regras da lógica, relação com textos para desenvolvimento de expressões (cf. NELSON, 1996; BINDEL et al., 2007).

Estas são as bases teóricas que correspondem aos atuais modelos de surgimento da teoria epigenética de aquisição da linguagem (cf. MUSSMANN, 2009, p. 156-175). O desenvolvimento até esta transição emotiva e até uma linguística pós-cognitivista, como base de uma didática de relacionamento com enfoque linguístico, foi representada recentemente na pedagogia para os distúrbios de fala e linguagem por Lüdtke (2010). Resumindo: as áreas de atuação e observação pedagógicas das deficiências linguísticas, cognitivas e socioemocionais coincidem. Uma forma escolar separativa para pessoas com distúrbios de linguagem na Alemanha é, portanto, teoricamente quase impossível de se justificar. O que já não ocorre com domínios exclusivos de especialização pedagógica, que analisam e apoiam, enfatizando diferentes prioridades, estas áreas de aprendizagem e desenvolvimento.

\section{PERSPECTIVAS}

\section{Recursos didáticos no sistema inclusive}

A verdadeira meta da discussão na Alemanha sobre inclusão é a escola para todos, uma escola que não vê diferenças, independente da idade, sexo, orientação religiosa, procedência social, língua materna, renda dos pais, status de moradia, desempenho cognitivo, doenças crônicas e até deficiências existentes. Todas as crianças e jovens são bem-vindos. Isto se estende até ao conceito integrador, como a aula para crianças com e sem deficiência. A escola inclusiva pode reunir sistemas de apoio subsidiários, baseados em rede, com pedagogos especiais móveis. O que se deve debater é se estes recursos devem ser estimulados também em casos de suporte através da 
facilitação linguística e terapias de linguagem, pelo sistema de saúde (através de fonoaudiólogos) ou ainda pelo sistema de ensino (através de pegagogos para distúrbios de fala e linguagem). Esta questão pode ser respondida fora da Alemanha: em outros países, os fonoaudiólogos trabalham nas escolas.

$\mathrm{Na}$ escola inclusiva, as condições próprias de uma heterogeneidade coletiva em uma relação de tensão pelos direitos individuais das crianças existem para poder estimular suas personalidades, seus dons e sua criatividade, bem como suas capacidades mentais e físicas, conforme o texto da convenção dos direitos das pessoas com deficiência (artigo 24, da convenção da ONU), que destaca este direito geral das pessoas com deficiência.

Como, porém, atingir esta total realização (volle Entfaltung) e de que maneira ela consiste em cada caso individual é uma questão com diferentes respostas, de acordo com cada criança, seu ambiente direto, sua escola e também possivelmente seus respectivos profissionais, cada um com suas perspectivas individuais, equilibrados em um processo de negociação mais ou menos explícito.

Uma pedagogia inclusiva com enfoque no suporte linguístico específico reflete (através de diagnóstico) e trabalha (aula, terapia) a relação de fatores indiretos (também chamados linguístico-estruturais e pessoais) e diretos, tanto distais quanto proximais (ou contexto), não necessariamente do uso da língua em grupos heterogêneos de aprendizado.

A criação e facilitação da tolerância da heterogeneidade linguística (cf. WEISSER, 2005) em suportes inclusivos requerem conhecimento técnico reflexivo, que integre objetos de estudo em todas as dimensões (linguística, medicina, psicologia) disciplinares (exclusivas), para dar condições a uma vivência comunicacional de sucesso, ou seja, a participação para poder descrever e refletir adequadamente dentro de um contexto profissional. Um conhecimento reflexivo exclusivo pode, portanto, requerer formas de tratamento exclusivas (terapia). A forma de tratamento especificada terapia da fala é subordinada ao suporte como uma forma acessivel de condições de desenvolvimento e aprendizagem comunicativo-linguísticos (sala de aula). (cf., p. ex., WELLING, 2007). Ambas as formas de tratamento podem apontar para uma qualidade pedagógica sólida. E elas ainda podem, quando permitem processos linguísticos de formação e aprendizagem em condições difíceis e as facilitam, visando apoiar esta aquisição, o desenvolvimento e a experimentação do conhecimento linguístico e das habilidades linguísticas, 
enfatizando sempre a autorreflexão da própria pessoa (o aluno). Sob este primado da autodeterminação e da determinação conjunta da linguagem, seguem as categorias de tratamento de níveis de habilitações (Figura 1) e a estrutura de uma pedagogia que tem como objetos de estudo os distúrbios na fala e na comunicação (Figura 2).

Uma pedagogia inclusiva que tenha como objetos de estudo as deficiências na língua e na comunicação deve, portanto, ser capaz de justificar um conceito profissional em um sistema de ensino inclusivo, cujo objeto de estudo (não necessariamente o uso da língua) englobe também as disciplinas relativas para uma reflexão objetiva, através da qual, entretanto, formas de tratamento (consultoria, apoio e terapia), que não necessitem de instituições exclusivas, têm de ser desviadas. Com relação às disciplinas correlatas relevantes que sejam necessárias para a identificação, análise e descrição da área de estudo (não necessariamente o uso da língua) no campo de tratamento prático da pedagogia para os distúrbios de fala e linguagem tradicional e separativa (linguística, ciência da educação, psicologia e as áreas médicas relacionadas, tais como neuropsicologia, aspectos da fonoaudiologia pediátrica e da foniatria), é constituído um aspecto profissional, cujas categorias de tratamento imanentes são viáveis (também a consultoria de professores e pais, suporte através de formação acadêmica direta, intervenções relacionadas à terapia como medidas individualizadas de apoio na sala de aula ou neste contexto), que estipulem formas de escolas inclusivas no campo de atuação da pedagogia geral e também nos conceitos de integração escolar e formas

Figura 1

\section{Relação com formação linguística, suporte e terapia}

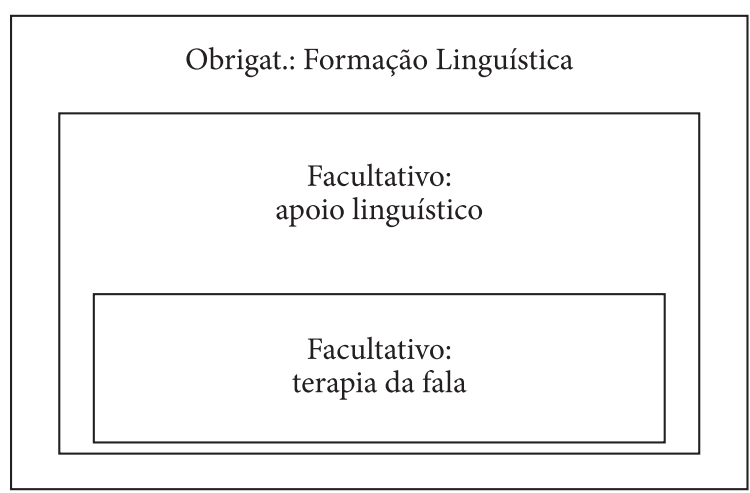




\section{Figura 2}

\section{Estrutura de uma pedagogia que tem como objetos de estudo os distúrbios na fala e na comunicação}

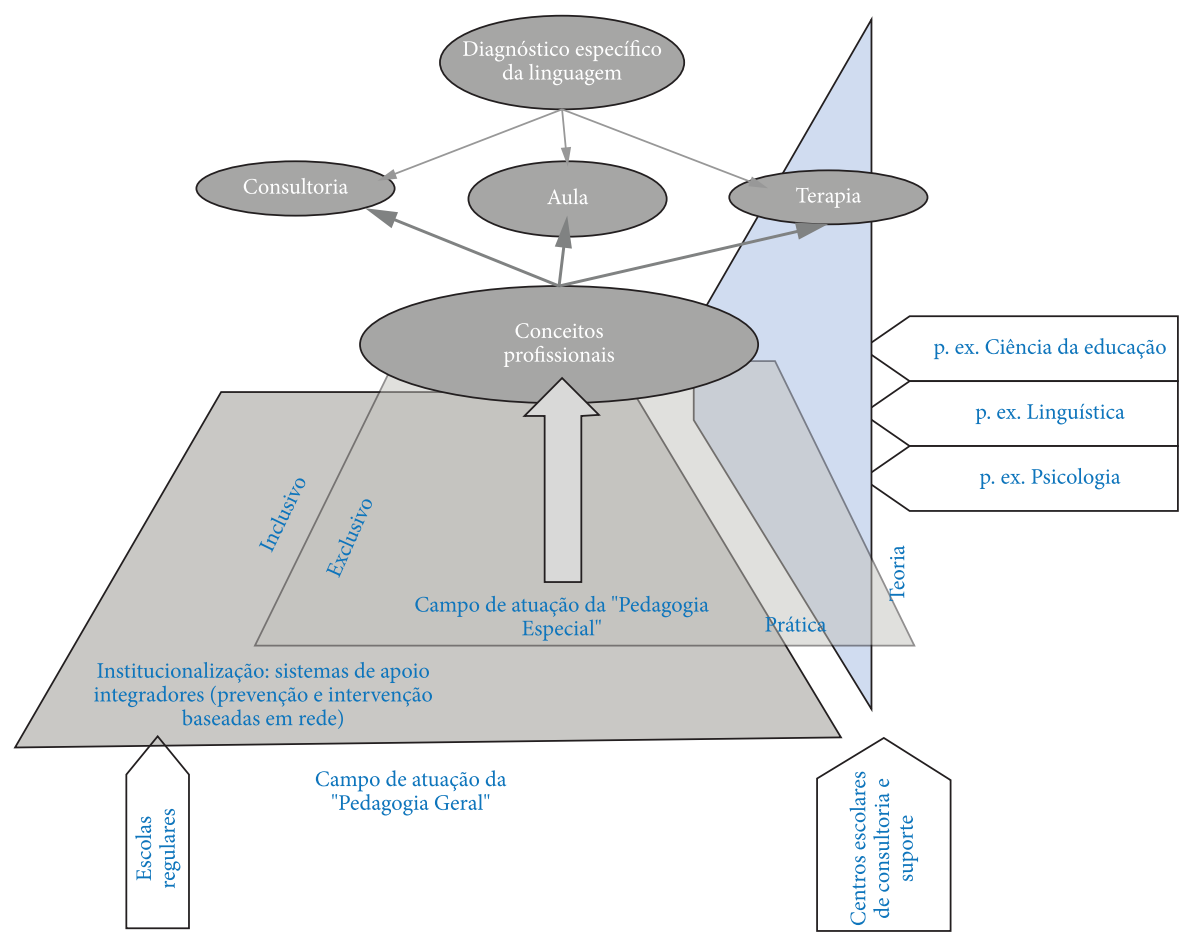

didáticas (sala de aula em comum). O trabalho pedagógico de tratamento dos distúrbios linguísticos não precisaria, para isso, necessariamente de escolas para portadores de distúrbios de fala e linguagem. Escolas de formação geral podem, entretanto, com base em seus programas escolares e especializações, prepararem-se para tais ofertas pedagógico-linguísticas ou fazer uso de apoios através de redes que sejam apropriadas e coordenadas por centros de suporte e consultoria.

A reflexão direta, não necessariamente quanto ao uso da língua, em uma situação de capacitação e educação na escola inclusive, requer categorias diretas e pessoais como terapia (Intervenção) e Facilitação (Suporte), para permitir diretamente a participação de todos. Uma pedagogia inclusiva para os distúrbios de fala e linguagem também pode oferecer uma aula terapêutico-linguística, que independa de instituições ou de locais de 
ensino (BRAUN, 2004, p. 50). Ela se diferencia do caráter preventivo do suporte linguístico como redução e impedimento de barreiras linguísticas (através de aulas adaptáveis) pela estrutura de sua intervenção específica: ela é uma espécie de sistema de apoio subsidiário in loco, se o aluno não tiver autonomia, para realização de estruturas linguísticas específicas frasais, fonológicas ou morfológicas e impedir qualquer barreira em um momento de crise que possa vir a atrapalhar seu processo de aprendizagem e formação. Isto poderia ocorrer casualmente (também em um caso de crise da fala ou da comunicação) ou constrastivamente como um desafio proposital. Em ambos os casos, uma eventual ajuda intuitiva da equipe de professores regulares diferencia-se, por já se saber quem, quando, por que e a quem, que tipo de assistência linguística será oferecida, especificamente devido a um diagnóstico prévio, e a quem não será preciso oferecê-la.

A reflexão indireta requer categorias de tratamento relacionadas ao contexto, tais como consultorias (de equipe de professores, professores qualificados e pais) para permitir sua participação direta. Assim, o trabalho é feito para a criança. Afinal, uma pedagogia para os distúrbios de fala e linguagem, de acordo com os critérios de avaliação fonético-fonológicos, semântico-lexicais, sintático-morfológicos e prosódicos, não pode se esgotar, assim como os trabalhos de saúde no campo da fonoaudiologia, na condição de conhecimento reflexivo necessário e exclusivo para grupos de aprendizagem linguisticamente heterogêneos em um sistema de ensino inclusivo, nem desviar objetivos terapêuticos específicos dos distúrbios, aos quais se adicionam os objetivos de educação e das aulas técnicas.

Eles devem, ao invés disso, estabelecer critérios para a formação de situações de aprendizagem e desenvolvimento, para confrontar os alunos com a mídia, temas e formas sociais com desafios comunicativos específicos da linguagem e a colocação de problemas, que lhes dê a oportunidade de ampliar e testar suas habilidades linguísticas individuais em contextos situacionais e temáticos. A pedagogia trata, primordialmente, através dos conhecimentos de fundo correspondentes da linguística, foniatria e psicologia, de quebrar as barreiras linguísticas na sala de aula seja indireta (através de consultoria) ou diretamente (através de trabalho em grupo na sala de aula), e de construir chances de aprendizagem e espaços de desenvolvimento. Os distúrbios de língua, fala e voz devem, neste caso, ser descritos e reconhecidos quanto à sua capacidade de criar barreiras durante a organização de aulas. O fato de que somente através de uma descrição exclusiva de uma situação-problema 
pedagógica com terminologia técnica já impedir a inclusão, e ainda o fato de se denominar e diferenciar, por exemplo, os gagos dos assim chamados tartamudos (disfêmicos) serve como fator excludente em sessões de consultoria com pedagogos tradicionais, o que não é compreensível e entra em sério conflito com os primeiros resultados empíricos baseados em avaliações de conceitos integradores (LÜTJE-KLOSE, 2008).

No entanto, não é o objetivo principal, de acordo com o diagnóstico e descrição da situação-problema, eliminar os distúrbios da fala como sendo um aspecto desta situação-problema, antes de serem feitos trabalhos de educação e treinamento. A fonoaudiologia dispõe, para isso, de muito mais recursos fora do ambiente escolar. A redução do distúrbio da fala e o desenvolvimento de estratégias de comunicação compensatórias são, entretanto, possíveis através e dentro da sala de aula. Para tanto, esta área desenvolveu conceitos profissionais compreensíveis, que se caracterizam por seus métodos imanentes e integrados com a aula, diferenciando esta qualidade pedagógica das terapias médicas feita pelos prestadores de tratamento.

\section{RECURSOS INSTITUCIONAIS: ESCOLAS SEPARADAS OU PREVENCฺ̃̃O E INTERVENÇÃO DESCENTRALIZADAS E BASEADAS EM REDES}

As escolas especiais da Alemanha com ênfase na linguagem dispõem de um tipo escolar com os mesmos objetivos didáticos e da assim chamada "Escola Especial de Transição"1, possuindo uma grande aceitabilidade pelos pais. Diversas escolas especializadas em distúrbios linguísticos possibilitam a obtenção de uma graduação qualificada em uma escola elementar ${ }^{2}$ ou em uma escola secundária moderna ${ }^{3}$ e oferecem, em cooperação com organizações regionais, medidas de preparação profissional com taxas de colocação comprovadamente positivas (cf. BACHMANN et al., 2001; JÄGER; BACHMANN, 2010). Por esta razão, tem-se falado muito que, em um sistema escolar reestruturado, esta forma de organização como sendo uma escola especialista (Angebotsschule) consiga se formar em uma escola de formação didática geral, tendo, por exemplo, um perfil de suporte linguístico em um sistema múltiplo de apoio e participação pedagógicos. Por outro lado, existe uma exigência de que os recursos didáticos que disponibilizam um domínio especializado da pedagogia na área das disfunções da língua e da fala, como explicado acima, sejam fornecidos necessariamente através de um sistema 
de apoio baseado em redes para a prevenção e intervenção, principalmente para alunos com disfunções no aprendizado escolar, para o desenvolvimento socioemocional, bem como de meios socialmente marginalizados e de crianças com um histórico de imigração. Uma vez que a equipe de professores de escolas regulares de hoje não pode suprir a demanda de apoio destas crianças sem medidas extensas e caras de requalificação, seria necessária a atuação de pedagogos especiais correspondentes, com enfoque na língua, em sistemas integradores e inclusivos. A já elucidada independência de instituições dos conceitos estruturados de apoio específicos para a língua em sala de aula (formação linguística individualizada e direta e suporte com relevância terapêutica, bem como consultoria indireta e relacionada ao contexto) compete tanto à sua recepção em uma já citada escola especialista ${ }^{4}$, quanto à sua implementação em um sistema inclusivo como rede subsidiária. Por último, fala-se também sobre a equiparação internacional. Lütje-Klose (1997) apresentou pesquisas sobre a efetividade e as concepções sobre a transferência de famílias dos EUA para a Alemanha, em cujas crianças e jovens foi realizada a terapia linguística por pessoal treinado na área terapêutica. Os modelos individuais, o desenvolvimento didático-escolar e as qualificações pedagógico-escolares dos profissionais situam-se, porém, abaixo do estágio de desenvolvimento da tradicional pedagogia para os distúrbios de fala e linguagem na Alemanha, o que, como já elucidado, vai contra a inserção de fonoaudiólogos e terapeutas acadêmicos da fala em escolas inclusivas na Alemanha. Em uma comparação internacional, podem ser identificados os seguintes sistemas escolares (cf. LÜTJE-KLOSE, 1997):

- o modelo pull out, no qual a terapia da fala acontece em grupos de suporte separados ou em situações individuais fora da sala de aula, mas ainda dentro da escola;

- o modelo classroom-based intervention, o uso duplo de profissionais em aulas regulares (team-teaching ou parallel-teaching integrador, cf. FRIEND; BURSUCK, 1999; LÜTJE-KLOSE; WILLENBRING, 1999); e

- o modelo collaborative consultation (cf. MARVIN, 1990), como forma mista de aulas dadas em conjunto com estruturas escolares de consultoria integradas entre especialistas em língua e o restante do conselho da equipe docente.

Estes modelos já estão sendo implementados também na Alemanha (como, por exemplo, através de serviços móveis (Mobiler Dienst), aulas em conjunto ou aulas regulares integradoras), porém devido à sua estrutura federativa, cada estado alemão possui seus traços, princípios e terminologias escolares diferentes. 
Ao lado de sistemas de apoio baseados em rede, por meio dos centros de consultoria, suporte ou competência, seus serviços móveis ou ambulâncias, que de acordo com a lei do ensino (decretos) são provisoriamente reparados, são desenvolvidos outros projetos-piloto e redes que, segundo os numerosos planos de ensino e educação nos estados federativos alemães ampliam sua área de atuação para escolas elementares e para ambientes extraescolares. Em diferentes níveis e pontos de transição, pode-se trabalhar diretamente com o suporte à criança ou, indiretamente, com consultoria ou formação contínua da equipe pedagógica docente para a criança.

- Em equipes de jardim de infância, através de sessões de consultoria e formações contínuas colegiais e específicas;

- Com os pais: são oferecidas reuniões de pais para informação e consultoria acerca dos temas desenvolvimento da língua, comportamentos promovidos pela comunicação e língua, riscos de desenvolvimento e carreira escolar;

- Com a própria criança no grupo do jardim de infância, ou na classe escolar, através de diagnósticos, estímulos individuais e terapia, ou sua intermediação; e

- Com representantes do maior número possível de instituições participantes: são planejadas conferências de suporte em conjunto, mas também reuniões cooperativas de educadores e futuros profissionais do ensino.

Todas as redes representam formas de transição rumo a um desenvolvimento escolar estrutural a longo prazo de locais de ensino, que possam reunir a formação e a educação de faixas etárias elementares e primárias. Estas redes para intermediação de recursos, consultoria e também de apoio individualizado compensam atualmente nada mais do que a diferença no treinamento e as áreas de competência entre os educadores e a equipe docente da escola primária, bem como concretamente a distância espacial e temporal de suas instituições.

Nos requisitos técnicos da análise e configuração deste processo de transição entre casa dos pais, jardim de infância, escola e trabalho em um sistema inclusivo, há uma grande chance de a pedagogia que trata das disfunções da língua e da fala introduzir seus recursos técnicos estabelecidos para crianças e jovens com condições agravadas de aquisição da primeira e segunda línguas. Da mesma forma, a atuação dessa especialidade pode se dar para sua equipe docente, além de expandir-se, através de sua orientação pedagógica decidida e competência didática, a ofertas no sistema de saúde. 


\section{REFERÊNCIAS}

ALBRECHT, F.; HINZ, A.; MOSER, V. Perspektiven der Sonderpädagogik. Disziplin- und professionsbezogene Standortbestimmungen. Neuwied; Berlin: Luchterhand, 2000.

ASTINGTON, J. The developmental interdependence of theory of mind and language. In: LEVINSON, S. C.; ENFIELD, N. J.The roots of human sociality: Culture, cognition, and human interaction. Oxford: Berg, 2006. p. 179-206.

BACHMANN, J. et al. Modell zur Verbesserung der Berufsreife von Schülerinnen und Schülern der Hauptstufe. Die Sprachheilarbeit, Berlin, v. 46, n. 5, p. 224-232, 2001.

BERG, M. Kontextoptimierung im Unterricht: Praxisbausteine für die Förderung grammatischer Fähigkeiten. München: Reinhardt, 2008.

BINDEL, R. Kognitives Modellieren als didaktisches Prinzip. In: KOHLBERG, T. Sprachtherapeutische Förderung im Unterricht. Stuttgart: Kohlhammer, 2007. p.144-160.

BINDEL, R.; KESSLER, L.; MUSSMANN, J. Zur Emergenz von Sprache. Forum Sprache, Ismaning, v. 1, p. 16-23, 2007.

BRAUN, O. Sprachtherapeutischer Unterricht in Theorie und Praxis. Bestandsaufnahme und Diskussion. In: DEUTSCHE GESELLSCHAFT FÜR SPRACHHEILPÄDAGOGIK E.V. Konzepte und Organisationsformen zur Rehabilitation Sprachbehinderter. Hamburg: Wartenberg, 1983. p. 167-178.

BRAUN, O. Bildung, Erziehung und Unterricht in der Sprachheilpädagogik. In: GROHNFELDT, M. Lebrbuch der Sprachbeilpädagogik und die Logopädie. Stuttgart; Berlin; Köln: Kohlhammer, 2004. v. 5, p. 25-51.

CAMARATA, S. M.; NELSON, K. E. Treatment efficiency as a function of target selection in the remediation of child language disorders. Clinical Linguistics and Phonetics, London, v. 6, p. 167-178, 1992.

CLAHSEN, H. Die Profilanalyse. Ein linguistisches Verfahren für die Sprachdiagnose im Vorschulalter. Berlin: Marhold, 1986.

DANNENBAUER, F. M. Grammatik. In: BAUMGARTNER, S.; FÜSSENICH, I. Sprachtherapie mit Kindern. München: Reinhardt, 1999. p. 123-203.

DRAVE, W. et al. Empfehlungen zur sonderpädagogischen Förderung. Würzburg: Bentheim, 2000. Allgemeine Grundlagen und Förderschwerpunkte (KMK) mit Kommentaren. Empfehlungen zum Förderschwerpunkt Sprache. 1998.

FRIEND, M.; BURSUCK, W. D. Students With Special Needs. Needham: Heights, 1999.

FROESCHELS, E. Lebrbuch der Sprachheilkunde. Leipzig: Deuticke, 1913.

GLÜCK, C.; MUSSMANN, J. Inklusive Bildung braucht exklusive Professionalität. Entwurf für eine, Inklusive Sprachheilpädagogik'. Die Sprachbeilarbeit, Berlin, v. 54, n. 5, p. 221-228, 2009.

GRAUMANN, C. F. Wieviel Zeigen steckt im Nennen? In: KORNADT, H.-J. et al. Sprache und Kognition. Heidelberg: Spektrum, 1994. p. 55-69.

GRIMM, H. Störungen der Sprachentwicklung. Grundlagen - Ursachen - Diagnose - Intervention - Prävention. Göttingen: Hogrefe, 2003.

GUTZMANN, A. Das Stottern und seine gründliche Beseitigung durch ein methodisch geordnetes und praktisch erprobtes Verfahren. Berlin, 1888. 
GUTZMANN, H. Sprachbeilkunde. Vorlesungen über die Störungen der Sprache mit besonderer Berücksichtigung der Therapie. Berlin: Kornfeld, 1912.

HOMBURG, G. Konvergenz von grundschul- und sprachheilpädagogischer Arbeit - ein Ansatzpunkt zu einer veränderten Grundschul- und Sprachheilpädagogik. Die Sprachbeilarbeit, Berlin, v. 38, n. 6, p. 279-296, 1993.

HINZ, A. Inklusive Pädagogik in der Schule. Veränderter Orientierungsrahmen für die schulische Sonderpädagogik!? Oder doch deren Ende? Zeitschrift für Heilpädagogik, Würzburg, n. 60, p. 171-179, 2009.

KUSSMAUL, A. Die Störungen der Sprache. Leipzig: Vogel, 1877.

LÜDTKE, U. Sprachdidaktiktheorie. Vom Sprachtherapeutischen Unterricht zur Relationalen Didaktik. Wie weiter in Zeiten der Inklusion? Zeitschrift für Heilpädagogik, Würzburg, n. 3, p. 84-96, 2010.

LÜTJE-KLOSE, B. Wege integrativer Sprach- und Kommunikationsförderung in der Schule. Konzeptionelle Entwicklungen und ihre Einschätzung durch amerikanische und deutsche ExpertInnen. St. Ingbert: Röhrig, 1997.

LÜTJE-KLOSE, B. Mobile sonderpädagogische Dienste im Förderschwerpunkt Sprache. Rekonstruktionen aus der Perspektive der durchführenden Sprachbehindertenpädagoginnen. Zeitschrift für Heilpädagogik, Würzburg, n. 8, p. 282-292, 2008.

LÜTJE-KLOSE, B.; WILLENBRING, M. Kooperation von Regelschullehrerin und Sprachbehindertenpädagogin. Eine wesentliche Bedingung für die integrative Sprach- und Kommunikationsförderung. Die Sprachheilarbeit, Berlin, v. 44, n. 2, p. 63-76, 1999.

MARVIN, C. A. Problems in School-based Spreech-Language Consultation and Collaboration Services: Defining the Terms and Improving the Process. In: SECORD, W. A.; WIIH, E. H. Collaborative Programs in the Schools Concepts, Models, and Procedures. San Antonio: Harcourt Brace Jovanovich, 1990. p. 37-47,

MOSER, V. Diagnostische Kompetenz als sonderpädagogisches Professionsmerkmal. In: MOSER, V.; VON STECHOW, E. Lernstands- und Entwicklungsdiagnosen. Bad Heilbrunn: Klinkhardt, 2005. p. 29-41.

MOTSCH, H.-J. Kontextoptimierung. Förderung grammatischer Fähigkeiten in Therapie und Unterricht. München: Reinhardt, 2006.

MUSSMANN, J. Sprache und Kommunikation in informellen Lern-und Bildungskontexten. Saarbrücken: Südwestdeutscher Verlag für Hochschulschriften, 2009.

MUSSMANN, J. Beqiehungsweise Sprache. Sprache als Medium sozial-emotionaler Entwicklung. Erscheint im Tagungsband der Fachtagung, 100 Jahre Sprachheilschule Halle - älteste Sprachheilschule Deutschlands. Halle, 2010.

NADOLECZNY, M. Kurzes Lehrbuch der Sprach- und Stimmbeilkunde. Leipzig: Vogel, 1926. NELSON, K. Language in cognitive development - emergence of the mediated mind. New York: Cambridge University Press, 1996.

ROTHE, K. C. Das Stottern, die assoziative Aphasie und ihre heilpädagogische Behandlung. Wien: Bundesverlag, 1925.

SLOBIN, D. I. From 'thought and language' to 'thinking to speaking'. In: GUMPERZ, J. J.; LEVINSON, S. C. Rethinking linguistic relativity. Cambridge: Cambridge University Press, 1996. p. 70-96. 
TOMASELLO, M. Die kulturelle Entwicklung des menschlichen Denkens. Frankfurt am Main: Suhrkamp, 2002.

UNGEHEUER, G. Sprechen, Mitteilen, Verstehen. Kommunikationstheoretische Schriften I. Aachener Studien zur Semiotik und Kommunikationsforschung. Aachen: Rader, 1987. WEISSER, J. Behinderung, Ungleichheit und Bildung. Eine Theorie der Behinderung. Bielefeld: Transcript, 2005.

WELLING, A.; KRACHT, A. Sprachpädagogische Professionalisierung der Sprachtherapie Kooperation als pädagogische Leitidee. In: ARBEITSKREIS KOOPERATIVE PÄDAGOGIK - AKOP E.V. Vom Wert der Kooperation Gedanken zu Bildung und Erziehung. Frankfurt am Main, 2002. p. 127-158.

WELLING, A. Einführung in die Sprachbehindertenpädagogik. München: Reinhardt, 2006.

WELLING, A. Unterricht und Therapie - die didaktische Frage im Förderschwerpunkt Sprache. In: SCHÖLER, H.; WELLING, A. Sonderpädagogik der Sprache. Göttingen: Hogrefe, 2007. p. 955-981.

WERNER, L. Aspekte der Integration von Therapie und Unterricht in der Schule für Sprachbehinderte sowie in schulorganisatorisch integrativ organisierten Einrichtungen. In: GIESEKE, T. Integrative Sprachtherapie. Tendenzen und Veränderungen in der Sprachheilpädagogik. Berlin: VWB, Verlag für Wiss. und Bildung, 1995. p. 109-121.

WEST, R. An historical review of the American literature in speech pathology. In: RIEBER, R.W.; BRUBAKER, R.S. Speech pathology: An international study of the science. Amsterdam: North-Holland Publishing Company, 1966. p. 24-41.

\section{NOTAS}

${ }^{1}$ Durchgangsschule
${ }^{2}$ Hauptschule
${ }^{3}$ Realschule
${ }^{4}$ Angebotsschule

Recebido: 20/10/2011 Aprovado: 15/05/2012 